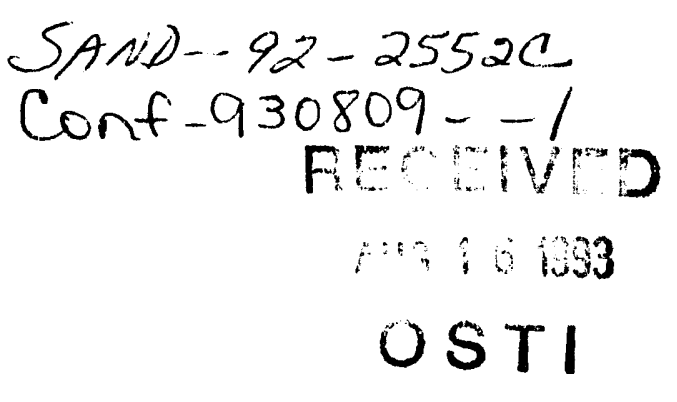

Patrick J. Griffin, ${ }^{1}$ and J. (Jake) G. Kelly ${ }^{2}$

\title{
Status of Neutron Dosimetry Cross Sections ${ }^{3}$
}

REFERENCE: Griffin, P. J., Kelly, J. G., "Status of Neutron Dosimetry Cross Sections," ReactorDosimetry ASTM STP 1228. Harry Farrar IV, E. Parvin Lippincott, and John G. Williams, Eds., American Society for Testing and Materials, Philadelphia, 1994.

\begin{abstract}
Several new cross section libraries, such as ENDF/B-VI (release 2), IRDF-90, JEF-2.2, and JENDL-3 Dosimetry, have recently been made available to the dosimetry community. The Sandia National Laboratories (SNL) Radiation Metrology Laboratory (RML) has worked with these libraries since pre-release vessions were available. This paper summarizes the results of the intercomparison and testing of dosimetry cross sections. As a result of this analysis, a compendium of the best dosimetry cross sections was assembled from the available libraries for use within the SNL RML. This library, referred to as the SNLRML Library, contains 66 general dosimetry sensors and 3 special dosimeters unique to the RML sensor inventory. The SNLRML cross sections have been put into a format compatible with commonly used spectrum determination codes.
\end{abstract}

KEYWORDS: cross sections, dosimetry, neutron, metrology, SANDII, spectrum adjustment, spectrum unfold, SNLRML, ENDF/B-VI, IRDF-90, DOSCROS84

Several new cross section libraries have been made available to the dosimetry community. These include the ENDF/B-VI [1,2], the International Reactor Dosimetry File (IRDF-90) [3], the Japanese Evaluated Nuclear Data Library (JENDL-3) [4], the USSR Evaluated Neutron Data Library (BROND) [5], the Joint Evaluated File (JEF-2.2) [6], an updated ORNL GLUCS [7] evaluation, International Library of Neutron Activation Cross Section Data for Fusion Reactor Applications (FENDL-2) [8], and Chinese Evaluated Nuclear Data Library (CENDL) $[9,10]$. Table 1 summarizes the available libraries, comments on the scope of the library and the issue date. Through their use as activation sensors for determining neutron spectra and fluence, these new dosimetry cross sections affect the characterization of neutron radiation damage facilities, the use of monitor foils to relate a given device irradiation to the specified environment, the comparison of device damage between reactor facilities, and the comparison of radiation-hardening test environments with anticipated operating environments.

The Sandia National Laboratories (SNL) Radiation Metrology Laboratory (RML) has worked with versions of these cross sections since pre-release data were available. These new cross sections have been compared with each other and evaluated with respect to their accuracy and consistency for spectrum unfolding applications. A compendium of dosimetry cross sections was assembled for use within the SNL Radiation Metrology Laboratory. This library, referred to as the SNLRML library [11], was empirically test-

'Senior Member of the Technical Staff, Sandia National Laboratories, Nuclear Systems Research Department, 6514, Albuquerque, NM 87185

${ }^{2}$ Distinguished Member of the Technical Staff, Sandia National Laboratories, Nuclear Systems Research Department, 6514, Albuquerque, NM 87185

${ }^{3}$ This work was performed at Sandia National Laboratories, which is operated for the U.S. Department of Energy under contract DE-AC04-76D00789.

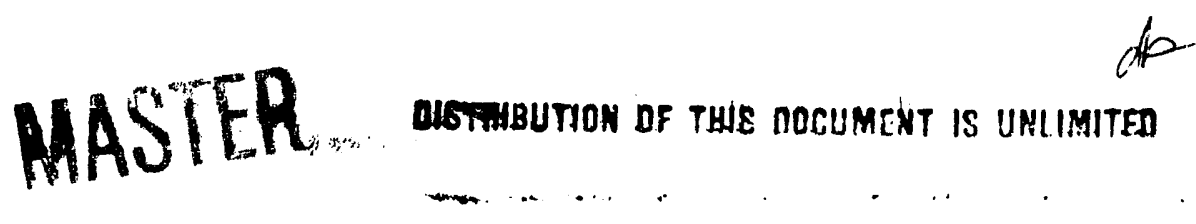


ed for use in fission spectrum determination and in the fluence and energy characterization of 14-MeV neutron sources [12]. The library has been prepared in a format that can be readily interfaced with both iterative spectrum unfolding codes, such as SAND-II [13], and least-squares codes, such as LSL-M2 [14].

TABLE 1: Available Cross Section Libraries

\begin{tabular}{|c|c|c|}
\hline \% Wrary & Commont & Yod. \\
\hline ENDF/B-VI & $\begin{array}{l}319 \text { evaluations, } \\
\text { replaced ENDF/B-V general purpose and dosimetry tape. }\end{array}$ & $\begin{array}{c}\text { June } 1990, \bmod 0 \\
\text { Sept. } 1991, \bmod 1 \\
\bmod 2 \text { tbd } \sim \text { July } 1993\end{array}$ \\
\hline IRDF-90 & $\begin{array}{l}\text { Replaced IRDF-82, } \\
44 \text { partial evaluations for reactor dosimetry. }\end{array}$ & $\begin{array}{c}1990 \\
1993 \text { mod tbd }\end{array}$ \\
\hline GLUCS & $\begin{array}{l}\text { ORNL dosimetry set, } \\
14 \text { reactions with cross isotope correlations, } \\
\text { source for new ENDF/B-VI, } \\
\text { update covariance in } 1993 \text {. }\end{array}$ & $\begin{array}{l}1990 \\
1993\end{array}$ \\
\hline JENDL-3 & 171 element Japanese Evaluated Library. & 1990 \\
\hline JENDL-DOS & 42 element JENDL Dosimetry Library. & 1992 \\
\hline JEF-2.2 & 344 element Joint Evaluated File by NEA. & Jan. 1993 \\
\hline BROND & 76 Russian evaluated cross sections. & $\begin{array}{l}1987 / 1990 \\
\text { mod tbd }\end{array}$ \\
\hline CENDL-2 & 50 element Chinese Evaluated Nuclear Data Library. & 1992 \\
\hline ENDF/B-V & Evaluated Nuclear Data File by CSEWG. & $1979-81$ \\
\hline IRDF-82 & 40 element International Reactor Dosimetry File. & 1982 \\
\hline ENDL & LLNL Evaluated Cross Sections [15]. & $1978-84$ \\
\hline DOSCROS84 & 74 element multi-group compendium of ENDF/B-V and IRDF-82 [16]. & 1984 \\
\hline Private Evaluations & $\begin{array}{l}\text { Includes pre-ENDF evaluations [17], } \\
\text { partial dosimetry-oriented evaluations [18, 19]. }\end{array}$ & $\cdots$ \\
\hline FENDL-2 & $\begin{array}{l}\text { International Library of Neutron Activation Cross Se_tion Data for Fusion } \\
\text { Reactor Applications. }\end{array}$ & 1992 \\
\hline
\end{tabular}

\section{DOSIMETRY-ORIENTED CROSS SECTION LIBRARIES}

Several of the cross section libraries were compiled with the specific purpose of supporting dosimetry applications. The CENDL-3 Library has a dosimetry-orientation but has not been completely analyzed and compared to other evaluations at the time this paper was written. The following sections briefly review the status of each of the other special dosimetry-oriented libraries that have been examined.

\section{ENDE/B-VI}

ENDF/B-VI is a replacement for the ENDF/B-V cross section library. ENDF/B-V had a special Dosimetry Library, an Activation Library, and a Fission Product Library. These libraries are no longer maintained as separate entities, but the ENDF documentation still identifies isotope/reaction combinations that comprise Dosimetry and Activation Libraries. Two ENDF/B-VI releases have already occurred and a third is expected soon. In cases where new evaluations were performed, the ENDF/B-VI library usually has the best dosimetry data. In cases where funding limitations did not permit new evaluations, a format translation was performed on the older ENDF/B-V evaluations. In these cases where a format translation was used to prepare the ENDF/B-VI evaluation, better sources of the dosimetry cross sections usually exist.

Some ommisions have occurred in the latest ENDF/B-VI release. The evaluator-recommended ${ }^{115} \operatorname{In}\left(n, n^{\prime}\right)^{115 m}$ In cross section was inadvertently omitted as part of a misunderstanding concerning allowed ENDF-6 formats. This should be remedied in the next release. The situation is confusing since pre-release versions of ENDF/B-VI contained this reaction in a comment section. Thus it was adopted by the IRDF-90 Library and an ENDF/B-VI reference is cited in associated documentation. A similar siluation exists for the ${ }^{47} \mathrm{Ti}(\mathrm{n}, \mathrm{p})^{47} \mathrm{Sc}$ and ${ }^{93} \mathrm{Nb}\left(\mathrm{n}, \mathrm{n}^{\prime}\right){ }^{93 \mathrm{~m}} \mathrm{Nb}$ reactions where again the evaluator-recommended cross section was inadvertently omitted in the current ENDF/B-VI release.

The ${ }^{32} \mathrm{~S}(\mathrm{n}, \mathrm{p})^{32} \mathrm{P}$ reaction found in the latest ENDF/B-VI release also has an interesting and confusing history. This reaction is discussed in detail in a following section. 


\section{DISCLAIMER}

This report was prepared as an account of work sponsored by an agency of the United States Government. Neither the United States Government nor any agency thereof, nor any of their employees, makes any warranty, express or implied, or assumes any legal liability or responsibility for the accuracy, completeness, or usefulness of any information, apparatus, product, or process disclosed, or represents that its use would not infringe privately owned rights. Reference herein to any specific commercial product, process, or service by trade name, trademark, manufacturer, or otherwise does not necessarily constitute or imply its endorsement, recommendation, or favoring by the United States Government or any agency thereof. The views and opinions of authors expressed herein do not necessarily state or reflect those of the United States Government or any agency thereof. 
The phase 1 reviewers of the ENDF/B-VI standard cross sections [which include ${ }^{197} \mathrm{Au}(\mathrm{n}, \gamma)^{198} \mathrm{Au}$, ${ }^{235} \mathrm{U}(\mathrm{n}, \mathrm{f}) \mathrm{FP}$, and ${ }^{238} \mathrm{U}(\mathrm{n}, \mathrm{f}) \mathrm{FP}$ reactions], have expressed concern that the uncertainties resulting from the combination of R-matrix and simultaneous evaluations might have led to uncertainties in the final evaluation that are too small. As a result, detailed covariance data will be added to the ENDF/B-VI files at a later time. The Standards Subcommittee (at the May 1990 CSEWG meeting) has produced a set of expanded covariance estimates for the standard cross section reactions. The uncertainty estimates are such that if a modern-day experiment were performed on a given standard cross section using the best techniques, approximately $2 / 3$ of the results should fall within these expanded uncertainties. These estimates can be found in the comment section of the ENDF/B-VI evaluation. A recent publication [20] documents the final ENDF/B-VI CSEWG-endorsed standard cross sections and uncertainties. As a result pre-release ENDF/B-VI covariance matrices for the standard cross sections were adopted by the IRDF-90 and cited as coming from ENDF/B-VI, but the latest ENDF/B-VI Library does not contain any covariance data for these reactions.

\section{GLUCS}

The GLUCS Library [7] was compiled at Oak Ridge National Laboratory and consists of 14 dosimetry cross sections that resulted from a simultaneous least-squares analysis of all of the reactions and included cross-correlations between the reactions. The 1990 version of the GLUCS results were often incorporated into the ENDF/B-VI and IRDF-90 compilations. H. Vonach discovered that some of the GLUCS covariance matrices were singular. D. Hetrick [21] traced the problem to the use of a ENDF/B-V covariance matrix that was not positive definite. A 1993 update to the GLUCS data, which was used in this analysis, provided new positive definite covariance matrices. There were no significant changes in the 1990 and 1993 GLUCS cross sections for most reactions, only the covariance matrices. One exception is for the ${ }^{47} \mathrm{Ti}(\mathrm{n}, \mathrm{p}){ }^{47} \mathrm{Sc}$ reaction where recent work by Mannhart [22] had a significant effect on the interpretation of the experimental database and was included in the 1992 GLUCS version. This reaction is discussed in more detail in a following section.

\section{IRDF-90}

The 1990 version of the International Reactor Dosimetry File (IRDF-90) represents the standard that is used in most laboratories for spectrum determination applications. This library drew upon a pre-release version of ENDF/B-VI and many private evaluations produced by the European dosimetry community. This library is distributed in ENDF- 6 format, but uses a tabular multi-group 640 energy group representation of the cross section that can readily be converted into a form that interfaces with spectrum determination codes. The one problem with this library is that it does not include many reactions in common use by the dosimetry community. It generally includes the highest quality dosimetry sensors, but analysts often must use other reactions to get good energy coverage for their spectrum determination. The use of sensors with good energy coverage is critical in the application of iterative spectrum unfolding methodologies. A 1993 version of IRDF is currently in beta-testing. This version is expected to update several dosimetry reactions. Reactions that are expected to be updated include the ${ }^{93} \mathrm{Nb}(\mathrm{n}, 2 \mathrm{n})^{92 \mathrm{~m}} \mathrm{Nb}$ and ${ }^{19} \mathrm{~F}(\mathrm{n}, 2 \mathrm{n})^{18} \mathrm{~F}$ reactions [23].

JENDL-3 Dosimetry

The JENDL-3 cross sections consist of several libraries, which include a General Purpose Library, a Dosimetry Library, Gas Production, and a Fission Product Library. JENDL-3 Dosimetry Library was released in 1992 and contains 42 dosimetry reaction evaluations. Many of these reaction cross sections are identical to those in the general purpose library. Much work has gone into this cross section library and most of the reaction evaluations are very recent and incorporate the latest experimental data.

In selecting sources for dosimetry cross sections for spectrum determination applications where other high quality evaluations existed, this analysis found two deficiencies in the JENDL-3 Dosimetry cross sections. First the authors of the JENDL-3 Dosimetry Library did not perform a detailed analysis of the covariance matrix for the specific reaction; rather they adopted the IRDF-85 covariance matrix. This decision may not correctly reflect the covariance in cases where new experimental data have resulted in significant changes in the evaluation. Second, whereas some evaluations, such as the IRDF-90 library, were often based on the application of a statistical methodology with careful selection/renormalization of experimental data $[23,24]$, the JENDL-3 Dosimetry library was often based on fitting of theoretical model calculations to the experimental data [25]. 


\section{DOSIMETRY REACTIONS}

A discussion and comparison of the cross sections for 66 commonly used dosimetry sensors can be found in reference 26 . A few dosimetry cross section reactions will be highlighted in this paper because their status has changed significantly.

${ }^{32} \mathrm{~S}(\mathrm{n} . \mathrm{p})^{32} \mathrm{P}$

The ${ }^{32} \mathrm{~S}(\mathrm{n}, \mathrm{p})^{32} \mathrm{P}$ dosimetry cross section is a very common sensor and is often used as a monitor foil. The community-recommended cross section has a very complicated and confusing history. There are three ENDF/B-V evaluations, one full evaluation, one in the activation library, and one in the dosimetry library. The activation and full evaluations are very similar, differing only near the reaction threshold energy. The dosimetry cross section differs significantly from the other two and shows considerable structure in the threshold region between 2 and $5 \mathrm{MeV}$. This ENDF/B-V Dosimetry Library ${ }^{32} \mathrm{~S}(\mathrm{n}, \mathrm{p})^{32} \mathrm{P}$ evaluation was the community standard. The ENDF/B-VI library required a full evaluation and thus adopted the older ENDF/ B-V full evaluation which differs from the cross section in the ENDF/B-V Dosimetry Library.

The most recent careful dosimetry cross section evaluation for ${ }^{32} \mathrm{~S}(\mathrm{n}, \mathrm{p})^{32} \mathrm{P}$ was done as part of the GLUCS cross-correlation study at ORNL. The ORNL cross section was adopted by the IRDF-90 community. The covariance data available with this latest GLUCS evaluation indicates that there is a very large $(\sim 30 \%)$ uncertainty in the cross section in the $2-6 \mathrm{MeV}$ region. The spectrum-averaged uncertainty for this cross section is $\sim 20 \%$ for fast-burst and pool-type fission spectra.

The use of new cross sections for the ${ }^{32} \mathrm{~S}(\mathrm{n}, \mathrm{p})^{32} \mathrm{P}$ reaction is complicated since this reaction is typically read with a beta counting system that uses a transfer calibration with a National Institute of Standards and Technology (NIST) ${ }^{252} \mathrm{Cf}$ irradiation. The fission spectrum-averaged cross section changes about the same amount as the ${ }^{252} \mathrm{Cf}$ spectrum-averaged cross section, thus the calibration procedure cancels out (to a large extent) the effect of the change in cross section (and hence the large uncertainty associated with the knowledge of the cross section). However, the calibration procedure introduces additional uncertainty related to the exact shape of the ${ }^{252} \mathrm{Cf}$ fission spectrum. Mannhart [27] has suggested changes in the ${ }^{252} \mathrm{Cf}$ spectrum relative to that currently employed by NIST for calibration purposes. The Mannhart ${ }^{252} \mathrm{Cf}$ fission neutron spectrum has been adopted by the ENDF/B-VI library (Tape 200, MAT=9861, MT=18, MF=5). This change in ${ }^{252} \mathrm{Cf}$ spectrum does not significantly affect the high energy part of the spectrum and results in less than $1 \%$ change in the ${ }^{32} \mathrm{~S}(\mathrm{n}, \mathrm{p})^{32} \mathrm{P}$ transfer calibration.

Some work on the ${ }^{32} \mathrm{~S}(\mathrm{n}, \mathrm{p})^{32} \mathrm{P}$ reaction by Fu [28] at ORNL differs from the ORNL/GLUCS/IRDF data at high energies $(>4.5 \mathrm{MeV})$. The difference in the Fu cross section at high energies can couple with the ${ }^{252} \mathrm{Cf}$ transfer calibration procedure to affect the fission spectrum-averaged cross section by a couple of percent. There is some indication that the Fu cross section, when properly related to the Sandia/NIST transfer calibration procedure, may provide better agreement with the $\mathrm{SNL}^{58} \mathrm{Ni}(\mathrm{n}, \mathrm{p})^{58} \mathrm{Co}$ monitor foil. The situation is not completely clear at this time since the effect is small and difficult to separate from fluctuations in counting statistics and transfer calibrations.

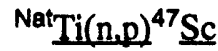

The SNL RML had not been able to use this dosimetry sensor for many years because it could not be made consistent with other foils. This poor agreement with experi nent has been confirmed, informally, by other laboratories. Mannhart [22] has shown that the disagreement related to difficulties in normalizing differential and integral data. He proposed a normalization change to the ENDF/B-V data. This change was found to make this reaction consistent with other dosimetry sensors in SNL spectrum unfolds. The spectrum-averaged ${ }^{47} \mathrm{Ti}(\mathrm{n}, \mathrm{p})^{47} \mathrm{Sc}$ cross section uncertainty for a fast-burst reactor (FBR) spectrum is $6.2 \%$, and for a pool-type spectrum it is 5.9\%. Experience with SAND-Il spectrum determination at the RML indicate agreement between measured and fitted activities to 6\%. Mannhart's analysis has been incorporated and ex.. tended in the GLUCS-90 release. The GLUCS/ORNL data have been, in turn, incorporated in the IRDF-90 library.

The IRDF-90 cross section file for ${ }^{47} \mathrm{Ti}$ indicates that the data were taken from ENDF/B-VI. This is an error in documentation, as was pointed out in a previous section. There is no new ENDF/B-VI ${ }^{47} \mathrm{Ti}$ evaluation; the ENDF/B-V data were adopted for ENDF/B-VI. New ${ }^{47} \mathrm{Ti}(\mathrm{n}, \mathrm{p})^{47} \mathrm{Sc}$ data should have appeared in the ENDF/B-VI cross sections, but was left out due to a miscommunication with the evaluators. 
The IRDF-90 library compilers went directly to the ENDF material evaluator for a pre-release version of the cross section and were not aware of the miscommunications. This situation should be remedied in release 2 of ENDF/B-VI.

An important consideration for many experimenters who use natural titanium foils is that the ${ }^{48} \mathrm{Ti}(\mathrm{n}, \mathrm{np})^{47} \mathrm{Sc}$ reaction produces the same activation product as ${ }^{47} \mathrm{Ti}(\mathrm{n}, \mathrm{p})^{47} \mathrm{Sc}$. This $(\mathrm{n}, \mathrm{np})$ contribution to the observed activity can be important for spectra with a high energy $(>12 \mathrm{MeV})$ component. Meadows and others [29] have advocated characterizing the ${ }^{\mathrm{Nat}} \mathrm{Ti}(\mathrm{n}, \mathrm{X})^{47} \mathrm{Sc}$ reaction while retaining a normalization to a per ${ }^{47}$ Ti atom in elemental titanium. A similar reporting convention has been adopted in the JENDL-3 Dosimetry Library, however, they report the cross section per elemental $\mathrm{Ti}$ atom and not per isotopic atom.

${ }^{58} \mathrm{Fe}(\mathrm{n}, y)^{59} \mathrm{Fe}$

The latest dosimetry-oriented ${ }^{58} \mathrm{Fe}(\mathrm{n}, \gamma){ }^{59} \mathrm{Fe}$ cross section has been evaluated by ORNL. This cross section was adopted by the ENDF/B-VI and the IRDF-90 libraries. The previous ENDF/B-V dosimetry library evaluation for this reaction was inconsistent with other dosimetry sensors in the resonance energy region and could not typically be used in spectrum unfolding. The new ENDF/B-VI evaluation must still be used with great caution. Work at SNL has indicated that the ENDF/B-VI cross section is consistent for spectrum determinations of pool-type reactors, such as the Annular Core Research Reactor (ACRR) central cavity, where the majority of the sensor response comes from the resonance region. However, for fast burst reactor spectra, such as the Sandia Pulsed Reactor (SPR) III central cavity, the sensor response is moved into the $200 \mathrm{keV}$ to $2.5 \mathrm{MeV}$ region and disagrees by $15 \%-30 \%$ with other foils in this region. The new cross section is a significant improvement over the ENDF/B-V dosimetry data, but it still has problems in the high energy region and should not be used for routine dosimetry. This result is consistent with an examination of the evaluator-specified covariance data for this reaction. The ${ }^{58} \mathrm{Fe}(\mathrm{n}, \gamma)^{59} \mathrm{Fe}$ spectrum-averaged cross section uncertainty for a fast-burst fission spectrum is $30 \%$, whereas for a pool-type fission spectrum is $9.4 \%$.

The consistency of the JENDL- ${ }^{58} \mathrm{Fe}(\mathrm{n}, \gamma)^{59} \mathrm{Fe}$ cross section with other dosimetry sensors has been evaluated. Examinations with SNL reactor spectra suggest that it has the same problem as the ENDF/B-VI data in fitting hard neutron spectra from fast-burst assemblies.

\section{Resonance Region Reactions}

Resonance region reactions such as ${ }^{59} \mathrm{Co}(\mathrm{n}, \gamma){ }^{60} \mathrm{Co},{ }^{55} \mathrm{Mn}(\mathrm{n}, \gamma){ }^{56} \mathrm{Mn},{ }^{58} \mathrm{Fe}(\mathrm{n}, \gamma){ }^{50} \mathrm{Fe},{ }^{45} \mathrm{Sc}(\mathrm{n}, \gamma)^{46} \mathrm{Sc}$, and ${ }^{23} \mathrm{Na}(\mathrm{n}, \gamma)^{24} \mathrm{Na}$ evaluation must be used with care. Work at $\mathrm{SNL}$ has indicated that the cross sections for these reactions are consistent for spectrum determinations of pool-type reactors, such as the ACRR central cavity, where the majority of the sensor response comes from the resonance region. However, for fast burst reactor spectra, such as the SPR-III central cavity, much of the sensor response is moved into the $100 \mathrm{keV}$ to $3.0 \mathrm{MeV}$ region and result in moderate disagreement with other foils in this region. These cross sections have self-consistency problems between the resonance region and the high energy region. Self-consistency between the resonance and $\mathrm{MeV}$ energy region for these resonance-region dosimetry reactions is an issue for evaluations in all of the available cross sections libraries, including JENDL-3 and ENDF. An examination of the evaluator-defined cross section covariance data confirms this lack of fidelity for the high-energy response of these sensors.

FIGURE 1: ${ }^{32} \mathrm{~S}(\mathrm{n}, \mathrm{p})^{32} \mathrm{p}$ Cross Section

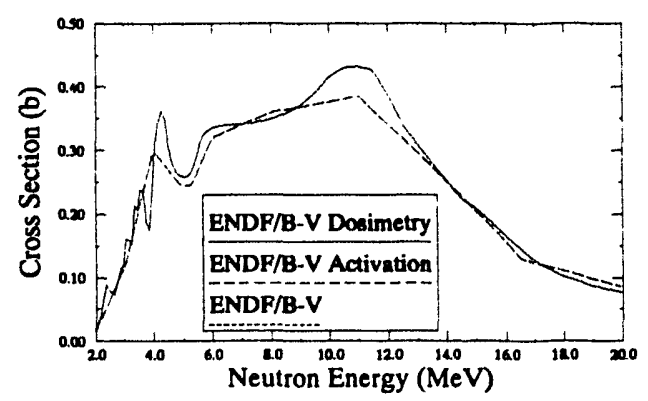

FIGURE 2: ${ }^{58} \mathrm{Fe}(\mathrm{n}, \gamma){ }^{59} \mathrm{Fe}$ Cross Section

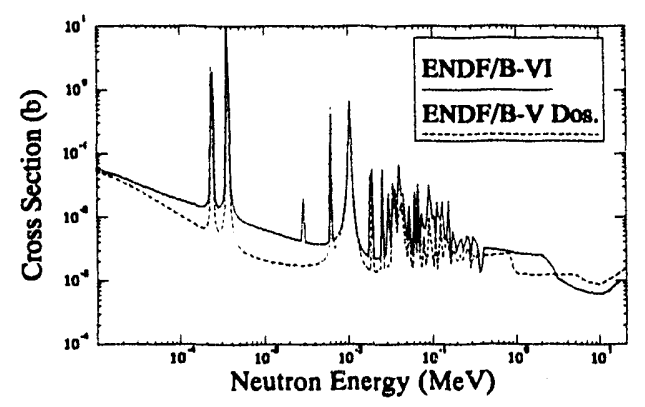




\section{Eission Reactions}

When a dosimetry laboratory uses fission foil sensors, they must consider the exact composition of fissile material in the sensor. At the RML, the depleted ${ }^{238} \mathrm{U}$ foil has a $0.2 \%{ }^{235} \mathrm{U}$ contaminant. When this foil is fielded, a boron ball is used to reduce the thermal neutron fluence. In the absence of a boron ball, a pool-type spectrum will result in half of the foil activity coming from the ${ }^{235} \mathrm{U}$ contaminant. Similarly, the RML ${ }^{239} \mathrm{Pu}$ foil has an $11.6 \%{ }^{240} \mathrm{Pu}$ contaminant. This component results in a significant change in the high energy foil fission cross section and must be considered in any foil analysis. Since ${ }^{240} \mathrm{Pu}$ has a small thermal fission cross section, unlike ${ }^{239} \mathrm{Pu}$, but a large high energy cross section, a mistake in modeling this contaminant will have different implications based on the type of spectrum being analyzed.

The correct fission yields for interpreting the dosimetry of fission foils depend upon the relative number of fissions produced in each fissionable component of the dosimeter. The SNL RML has calculated the relative division of fissions between the dosimeter components in fast burst and pool-type spectra when fielded as bare sensors and in boron balls. This fission density is used at the RML to weight the ENDF/B-VI fission yields (cumulative and relative) and to convert a fission product gamma decay measurement into a fission reaction rate.

\section{SNLRML LIBRARY}

As a result of this comparison of dosimetry cross sections from all available high-quality evaluations, a cross section library has been assembled that represents, in the authors' view, the best cross sections to be used for spectrum determination. This library is referred to as the SNLRML Library. Documentation has been prepared to provide a quality assurance audit trail for the use of these cross sections. Extensive testing in fission environments (from fast burst and pool-type reactors) and in 14-MeV DT neutron spectra has been performed to assure the best possible consistency in the selection of cross sections.

\section{Contents}

The SNLRML Library contains a set of 66 dosimetry sensors (and 3 special composite fission foil sensors unique to the RML sensor inventory) drawn from the most recent cross section evaluations. Covariance matrices are included to support the requirements of least-squares unfolding codes. In cases where covariance data were not available for the selected cross section evaluation, an alternate source for the covariance data has sometimes been used temporarily to estimate the data covariance matrix. Table 2 shows the contents of the library and indicates the source of the cross sections and covariance data. The contents of the library include activation, fission and threshold dosimetry reactions, standard exposure parameters, and absorption cross sections for cover materials ( $\mathrm{Au}, \mathrm{Cd}$, and $\mathrm{B}$ ) often used to move a dosimetry sensor's response to higher energy. The SNLRML library has been tested by unfolding over twenty-five reactor neutron spectra and comparing the resulting spectra with previous determinations. This comparison has been presented to the dosimetry community and peer-reviewed $[11,12]$.

\section{Eormat}

All information is provided in ASCII format to facilitate library portability. The NJOY [30] code was used to process the ENDF- 6 format cross sections into the 640 energy group SAND-II energy structure, which is used to represent all reaction cross sections. Covariance matrices, also NJOY processed, are represented as a normalized upper triangular matrix and use a reaction-specific energy group structure to allow a high-fidelity representation with minimal storage requirements. The library format was designed to provide all of the information required by either iterative unfolding codes, such as SAND-II, or least-squares adjustment codes, such as LSL-M2. This library should be easily interfaced with either type of code. The inp it format consists of blank-delimited free-field quantities compatible with the SAND-II input processor.

Availability

The SNLRML library cross section compendium is being submitted to the Radiation Shielding Information Cenier (RSIC) operated by Oak Ridge National Laboratory and should soon be available to the dosimetry community. 
TABLE 2: Contents of the SNLRML Library

\begin{tabular}{|c|c|c|c|c|c|c|c|}
\hline \multicolumn{2}{|r|}{$\begin{array}{l}\text { porimerty } \\
\text { zeactions }\end{array}$} & \multirow{2}{*}{$\begin{array}{l}\text { Source } \\
\text { (16rary } \\
\text { ENDF/B-VI } \\
\end{array}$} & \multirow{2}{*}{ 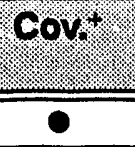 } & \multicolumn{2}{|r|}{$\begin{array}{l}\text { pormory } \\
\text { Reactons }\end{array}$} & \multirow{2}{*}{ 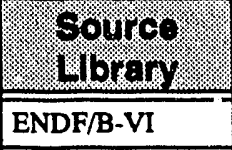 } & \multirow{2}{*}{$\frac{90 \% \%^{2}}{0}$} \\
\hline 1. & ${ }^{10} \mathrm{~B}(\mathrm{n}, \mathrm{abs})$ & & & 36. & ${ }^{63} \mathrm{Cu}(\mathrm{n}, \gamma)^{64} \mathrm{Cu}$ & & \\
\hline 2. & ${ }^{10} \mathrm{~B}(\mathrm{n}, \mathrm{X}){ }^{4} \mathrm{He}$ & ENDF/B-VI & 0 & 37. & ${ }^{63} \mathrm{Cu}(n, 2 n)^{62} \mathrm{Cu}$ & IRDF-90 & 0 \\
\hline 3. & ${ }^{11} \mathrm{~B}(\mathrm{n}, \mathrm{abs})$ & ENDF/B-VI & $\cdots$ & 38. & ${ }^{63} \mathrm{Cu}(\mathrm{n}, \alpha)^{60} \mathrm{Co}$ & IRDF-90 & 9 \\
\hline 4. & Nat $_{B(n, a b s)}$ & ENDF/B-VI & 0 & 39. & ${ }^{65} \mathrm{Cu}(\mathrm{n}, 2 \mathrm{n})^{64} \mathrm{Cu}$ & ENDF/B-VI & GLUCS \\
\hline 5. & ${ }^{e^{-n i c h}} \mathrm{~B}_{4} \mathrm{C}(\mathrm{n}, \mathrm{abs})$ & ENDF/B-VI & 0 & 40. & ${ }^{64} \mathrm{Zn}(\mathrm{n}, \mathrm{p}){ }^{64} \mathrm{Cu}$ & IRDF-90 & - \\
\hline 6. & ${ }^{6} \mathrm{Li}(\mathrm{n}, \mathrm{X})^{4} \mathrm{He}$ & ENDF/B-VI & - & 41. & ${ }^{80} \mathrm{Zr}(\mathrm{n}, 2 \mathrm{n})^{89} \mathrm{Zr}$ & IRDF-90 & 9 \\
\hline 7. & ${ }^{19} F(n, 2 n)^{18} F$ & IRDF-90 & 0 & 42. & GaAs(n,X)1MeV & Private & $\ldots$ \\
\hline 8. & ${ }^{23} \mathrm{Na}(\mathrm{n}, \gamma)^{24} \mathrm{Na}$ & ENDF/B-VI & - & 43. & ${ }^{93} \mathrm{Nb}(\mathrm{n}, \gamma)^{94} \mathrm{Nb}$ & ENDF/B-VI & 0 \\
\hline 9. & ${ }^{24} \mathrm{Mg}(\mathrm{n}, \mathrm{p}){ }^{24} \mathrm{Na}$ & IRDF-90 & 0 & 44. & ${ }^{93} \mathrm{Nb}(\mathrm{n}, 2 \mathrm{n})^{92 m_{\mathrm{Nb}}}$ & IRDF-90 & 0 \\
\hline 10. & ${ }^{27} \mathrm{Al}(\mathrm{n}, \mathrm{p})^{27} \mathrm{Mg}$ & GLUCS/IRDF-90 & 0 & 45. & ${ }^{93} \mathrm{Nb}\left(\mathrm{n}, \mathrm{n}^{\prime}\right)^{93 \mathrm{~m}} \mathrm{Nb}$ & IRDF-90 & 0 \\
\hline 11. & ${ }^{27} \mathrm{Al}(\mathrm{n}, \alpha)^{24} \mathrm{Na}$ & IRDF-90 & 0 & 46. & ${ }^{98} \mathrm{Mo}(\mathrm{n}, \gamma)^{99} \mathrm{Mo}$ & JENDL-3 & $\ldots$ \\
\hline 12. & ${ }^{\text {Nat }}$ Si(n, X)1MEV & private, ORNL & $\cdots$ & 47. & ${ }^{103} \mathrm{Rh}\left(\mathrm{n}, \mathrm{n}^{\prime}\right)^{103 m_{\mathrm{Rh}}}$ & IRDF-90 & 0 \\
\hline 13. & ${ }^{31} \mathrm{P}(\mathrm{n}, \mathrm{p})^{31} \mathrm{Si}$ & IRDF-90 & 0 & 48. & ${ }^{109} \mathrm{Ag}(\mathrm{n}, \gamma){ }^{110 m} \mathrm{Ag}$ & DOSCROS84 & $\cdots$ \\
\hline 14. & ${ }^{32} S(n, p)^{32} p$ & GLUCS/IRDF-90 & 0 & 49. & ${ }^{\text {Nat }} \mathrm{Cd}(\mathrm{n}, \mathrm{abs})$ & JENDL-3 & $\cdots$ \\
\hline 15. & ${ }^{45} \mathrm{Sc}(\mathrm{n}, \gamma){ }^{46} \mathrm{Sc}$ & ENDF/B-VI & 0 & 50. & ${ }^{115} \ln (n, \gamma){ }^{116 m_{I n}}$ & ENDF/B-VI & 0 \\
\hline 16. & ${ }^{46} \mathrm{Ti}(\mathrm{n}, \mathrm{p})^{46} \mathrm{Sc}$ & GLUCS/IRDF-90 & 9 & 51. & ${ }^{115} \operatorname{In}\left(n, n^{\prime}\right)^{115 m_{I n}}$ & IRDF-90 & 2 \\
\hline 17. & ${ }^{47} \mathrm{Ti}(\mathrm{n}, \mathrm{p})^{47} \mathrm{Sc}$ & IRDF-90 & GLUCS & 52. & ${ }^{127} I(n, 2 n)^{126_{I}}$ & ENDF/B-VI & E5 \\
\hline 18. & ${ }^{47} \mathrm{Ti}(\mathrm{n}, \mathrm{np}){ }^{46} \mathrm{Sc}$ & ENDF/B-VI & 0 & 53. & ${ }^{197} \mathrm{Au}(\mathrm{n}, \mathrm{p}){ }^{197} \mathrm{Pt}$ & ENDF/B-VI & $--\cdot$ \\
\hline 19. & ${ }^{\mathrm{Nat}} \mathrm{Ti}(\mathrm{n}, \mathrm{X})^{46} \mathrm{Sc}$ & private & $\cdots$ & 54. & ${ }^{197} \mathrm{Au}(\mathrm{n}, \gamma){ }^{198} \mathrm{Au}$ & ENDF/B-VI & IRDF-90 \\
\hline 20. & ${ }^{48} \mathrm{Ti}(\mathrm{n}, \mathrm{p}){ }^{48} \mathrm{Sc}$ & GLUCS/IRDF 90 & GLUCS & 55. & ${ }^{197} \mathrm{Au}(\mathrm{n}, 2 \mathrm{n}){ }^{196} \mathrm{Au}$ & IRDF-90 & 0 \\
\hline 21. & ${ }^{48} \mathrm{Ti}(\mathrm{n}, \mathrm{np}){ }^{47} \mathrm{Sc}$ & ENDF/B-VI & 0 & 56. & ${ }^{197} \mathrm{Au}(\mathrm{n}, 3 \mathrm{n})^{195} \mathrm{Au}$ & ENDF/B-VI & $\ldots$ \\
\hline 22. & ${ }^{\mathrm{Nat}} \mathrm{Ti}(\mathrm{n}, \mathrm{X})^{47} \mathrm{Sc}$ & private & $\cdots$ & 57. & ${ }^{\text {Nat }} \mathrm{Au}(\mathrm{n}, \mathrm{abs})$ & ENDF/B-VI & - \\
\hline 23. & ${ }^{55} \mathrm{Mn}(\mathrm{n}, \gamma){ }^{56} \mathrm{Mn}$ & ENDF/B-V & E6 & 58. & ${ }^{232} \mathrm{Th}(\mathrm{n}, \mathrm{\gamma})^{233} \mathrm{Th}$ & ENDF/B-VI & 0 \\
\hline 24. & ${ }^{55} \mathrm{Mn}(\mathrm{n}, 2 \mathrm{n})^{54} \mathrm{Mn}$ & ENDF/B-VI & - & 59. & ${ }^{232} \operatorname{Th}(n, 2 n)^{231} T h$ & ENDF/B-VI & $\cdots$ \\
\hline 25. & ${ }^{54} \mathrm{Fe}(\mathrm{n}, \mathrm{p}){ }^{54} \mathrm{Mn}$ & ENDF/B-VI & GLUCS & 60. & ${ }^{232} \operatorname{Th}(\mathrm{n}, \mathrm{f}) \mathrm{F} . \mathrm{P}$. & ENDF/B-VI & 0 \\
\hline 26. & ${ }^{56} \mathrm{Fe}(\mathrm{n}, \mathrm{p}){ }^{56} \mathrm{Mn}$ & ENDF/B-VI & GLUCS & 61. & ${ }^{235} \mathrm{U}(\mathrm{n}, \mathrm{f}) \mathrm{F} . \mathrm{P}$. & ENDF/B-VI & IRDF90 \\
\hline 27. & ${ }^{58} \mathrm{Fe}(\mathrm{n}, \gamma){ }^{59} \mathrm{Fe}$ & ENDF/B-VI & 0 & 62. & ${ }^{238} \mathrm{U}(\mathrm{n}, \mathrm{f}) \mathrm{F} . \mathrm{P}$. & ENDF/B-VI & IRDF90 \\
\hline 28. & ${ }^{\text {Nat }} \mathrm{Fe}(\mathrm{n}, \mathrm{X}) \mathrm{dpa}$ & ASTM E 693 & $\cdots$ & 63. & ${ }^{237} \mathrm{~Np}(\mathrm{n}, \mathrm{f}) \mathrm{F} . \mathrm{P}$. & ENDF/B-VI & E5d \\
\hline 29. & ${ }^{59} \mathrm{Co}(n, p){ }^{59} \mathrm{Fe}$ & ENDF/B-VI & 9 & 64. & ${ }^{239} \mathrm{Pu}(\mathrm{n}, \mathrm{f})$ F.P. & ENDF/B-VI & JENDL-3d \\
\hline 30. & ${ }^{59} \mathrm{Co}(\mathrm{n}, \gamma)^{60} \mathrm{Co}$ & ENDF/B-VI & E5 & 65. & ${ }^{241} \mathrm{Am}(\mathrm{n}, \mathrm{f}) \mathrm{F} . \mathrm{P}$. & ENDF/B-VI & 0 \\
\hline 31. & ${ }^{59} \mathrm{Co}(\mathrm{n}, \alpha)^{56} \mathrm{Mn}$ & ENDF/B-VI & 0 & 66. & RMLEU*, ${ }^{235} \mathrm{U}(\mathrm{n}, \mathrm{f})$ & ENDF/B-VI & IRDF90 \\
\hline 32. & ${ }^{59} \mathrm{Co}(n, 2 n){ }^{58} \mathrm{Co}$ & IRDF-90 & 9 & 67. & RMLDU ${ }^{*},{ }^{238} U(n, f)$ & ENDF/B-VI & IRDF90 \\
\hline 33. & ${ }^{58} \mathrm{Ni}(\mathrm{n}, \mathrm{p}){ }^{58} \mathrm{Co}$ & ENDF/B-VI & GLUCS & 68. & RMLPU", ${ }^{230} \mathrm{Pu}(\mathrm{n}, \mathrm{f})$ & ENDF/B-VI & JENDL-3d \\
\hline 34. & ${ }^{58} \mathrm{Ni}(\mathrm{n}, 2 \mathrm{n})^{57} \mathrm{Ni}$ & ENDF/B-VI & 0 & 69. & ${ }^{32} \mathrm{~S}-3 \mathrm{MeV}$ & GLUCS/IRDF-90 & 9 \\
\hline 35. & ${ }^{60} \mathrm{Ni}(\mathrm{n}, \mathrm{p})^{60} \mathrm{Co}$ & ENDF/B-V' & 9 & & & & \\
\hline . & \% & d from 8 & $\ldots$ & ent & $\begin{array}{l}\text { Io Data } \\
\text { compositions } 1\end{array}$ & Muro ail nissile & । \\
\hline
\end{tabular}


TABLE 3: Variation in Dosimetry Cross Section Evaluations

\begin{tabular}{|c|c|c|c|c|c|c|c|}
\hline & 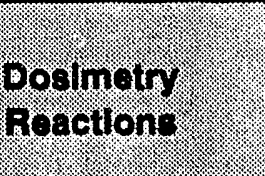 & \%10 & ection. & 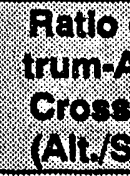 & $\begin{array}{l}\text { Spor. } \\
\text { regr. } \\
\text { antor. }\end{array}$ & 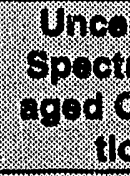 & 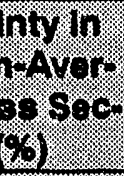 \\
\hline & & ancrnate & SNLRML & $\mathrm{PBH}$ & Pood & 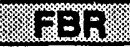 & moal \\
\hline 1. & ${ }^{19} F(n, 2 n)^{18} F$ & JENDL-3d & IRDF-90 & 1.137 & 1.146 & 5.78 & 5.84 \\
\hline 2. & ${ }^{23} \mathrm{Na}(\mathrm{n}, y)^{24} \mathrm{Na}$ & JENDL-3d & ENDF/B-VI & 0.79719 & 1.0026 & 15.55 & 2.94 \\
\hline 3. & ${ }^{24} \mathrm{Mg}(\mathrm{n}, \mathrm{p})^{24} \mathrm{Na}$ & JENDL-3d & IRDF-90 & 1.0656 & 1.060 & 3.72 & 3.54 \\
\hline 4. & ${ }^{27} \mathrm{Al}(\mathrm{n}, \mathrm{p})^{27} \mathrm{Mg}$ & JENDL-3d & GLUCS & 1.0756 & 1.071 & 10.83 & 12.10 \\
\hline 5. & ${ }^{27} \mathrm{Al}(\mathrm{n}, \alpha)^{24} \mathrm{Na}$ & JENDL-3d & IRDF-90 & 0.9552 & 0.9563 & 2.61 & 2.50 \\
\hline 6. & ${ }^{\mathrm{Nal}} \mathrm{Si}(\mathrm{n}, \mathrm{X}) 1 \mathrm{MEV}$ & $\begin{array}{c}\text { ASTM } \\
\text { E 722-85 } \\
\end{array}$ & $\begin{array}{c}\text { ASTM } \\
\text { E 722-93 } \\
\end{array}$ & 1.0973 & 1.0829 & $\ldots$ & $\ldots$ \\
\hline 7. & ${ }^{31} \mathrm{P}(\mathrm{n}, \mathrm{p})^{31} \mathrm{Si}$ & JENDL-3d & IRDF-90 & 1.294 & 1.303 & 7.03 & 7.10 \\
\hline 8. & ${ }^{32} S(n, p)^{32} p$ & JENDL-3d & GLUCS & 1.0735 & 1.0705 & 19.41 & 19.60 \\
\hline 9. & ${ }^{45} S c(n, \gamma)^{46} S c$ & JENDL-3d & ENDF/B-VI & 1.21 & 0.9993 & 4.20 & 1.05 \\
\hline 10. & ${ }^{\mathrm{Nal}} \mathrm{Ti}(\mathrm{n}, \mathrm{X})^{46} \mathrm{Sc}$ & JENDL-3d & Private & 1.0805 & 1.082 & 4.51 & 4.87 \\
\hline 11. & ${ }^{48} \mathrm{Ti}(\mathrm{n}, \mathrm{p})^{48} \mathrm{Sc}$ & JENDL-3d & GLUCS & 1.0221 & 1.023 & 4.04 & 4.12 \\
\hline 12. & ${ }^{\mathrm{Nat}} \mathrm{Ti}(\mathrm{n}, \mathrm{X})^{47} \mathrm{Sc}$ & $\begin{array}{l}\text { JENDL-3d } \\
\text { ENDF/B-Vd } \\
\end{array}$ & Private & $\begin{array}{l}1.071 \\
1.235 \\
\end{array}$ & $\begin{array}{c}1.071 \\
1.2332 \\
\end{array}$ & 6.20 & 5.94 \\
\hline 13. & ${ }^{55} \mathrm{Mn}(\mathrm{n}, \gamma)^{56} \mathrm{Mn}$ & JEF 2.2 & ENDF/B-Va & 1.2167 & 1.023 & 14.75 & 5.51 \\
\hline 14. & ${ }^{55} \mathrm{Mn}(\mathrm{n}, 2 \mathrm{n})^{54} \mathrm{Mn}$ & JENDL-3d & ENDF/B-VI & 0.99927 & 0.9992 & 20.98 & 21.21 \\
\hline 15. & ${ }^{54} \mathrm{Fe}(\mathrm{n}, \mathrm{p})^{54} \mathrm{Mn}$ & JENDL-3d & ENDF/B-VI & 0.994 & 0.9909 & 3.05 & 3.11 \\
\hline 16. & ${ }^{56} \mathrm{Fe}(\mathrm{n}, \mathrm{p})^{56} \mathrm{Mn}$ & JENDL-3d & ENDF/B-VI & 1.0185 & 1.0241 & 4.29 & 4.08 \\
\hline 17. & ${ }^{58} \mathrm{Fe}(\mathrm{n}, \gamma){ }^{59} \mathrm{Fe}$ & $\begin{array}{c}\text { JENDL-3d } \\
\text { ENDF/B-Vd }\end{array}$ & ENDF/B-VI & $\begin{array}{c}0.968 \\
0.6239 \\
\end{array}$ & $\begin{array}{l}1.106 \\
0.9458 \\
\end{array}$ & 29.21 & 9.45 \\
\hline 18. & ${ }^{59} \mathrm{Co}(\mathrm{n}, \mathrm{p}){ }^{59} \mathrm{Fe}$ & $\begin{array}{c}\text { JENDL-3 } \\
\text { ENDF/B-Va }\end{array}$ & ENDF/B-VI & $\begin{array}{l}1.377 \\
1.080 \\
\end{array}$ & $\begin{array}{l}.0442 \\
1.0939 \\
\end{array}$ & 4.96 & 5.02 \\
\hline 19. & ${ }^{59} \mathrm{Co}(\mathrm{n}, \gamma){ }^{60} \mathrm{Co}$ & JENDL-3d & ENDF/B-VI & 1.039 & 1.002 & 2.80 & 0.76 \\
\hline 20. & ${ }^{58} \mathrm{Co}(\mathrm{n}, \alpha)^{56} \mathrm{Mn}$ & JENDL-3d & ENDF/B-VI & 1.0815 & 1.072 & 4.46 & 4.44 \\
\hline 21. & ${ }^{59} \mathrm{Co}(n, 2 n)^{58} \mathrm{Co}$ & JENDL-3d & IRDF-90 & 0.9947 & 0.9942 & 4.60 & 4.67 \\
\hline 22. & ${ }^{58} \mathrm{Ni}(\mathrm{n}, \mathrm{p})^{58} \mathrm{Co}$ & JENDL-3d & ENDF/B-VI & 1.0025 & 1.004 & 4.49 & 4.56 \\
\hline 23. & ${ }^{58} \mathrm{Ni}(n, 2 n)^{57} \mathrm{Ni}$ & JENDL-3d & ENDF/B-VI & 0.962 & 0.9617 & 4.18 & 4.18 \\
\hline 24. & ${ }^{60} \mathrm{Ni}(\mathrm{n}, \mathrm{p})^{60} \mathrm{Co}$ & JENDL-3d & ENDF/B-VI & 1.338 & 1.337 & 15.02 & 15.02 \\
\hline 25. & ${ }^{63} \mathrm{Cu}(\mathrm{n}, \gamma){ }^{64} \mathrm{Cu}$ & JENDL-3d & ENDF/B-VI & 0.8024 & 0.9988 & 15.06 & 5.34 \\
\hline 26. & ${ }^{63} \mathrm{Cu}(\mathrm{n}, 2 \mathrm{n}){ }^{62} \mathrm{Cu}$ & JENDL-3d & IRDF-90 & 1.057 & 1.057 & 3.63 & 3.67 \\
\hline 27. & ${ }^{63} \mathrm{Cu}(\mathrm{n}, \alpha)^{60} \mathrm{Co}$ & JENDL-3d & ENDF/B-VI & 1.0566 & 1.068 & 4.08 & 4.16 \\
\hline 28. & ${ }^{65} \mathrm{Cu}(\mathrm{n}, 2 \mathrm{n})^{64} \mathrm{Cu}$ & JENDL-3d & ENDF/B-VI & 1.0336 & 1.0337 & 3.97 & 3.99 \\
\hline 29. & ${ }^{64} \mathrm{Zn}(\mathrm{n}, \mathrm{p}){ }^{64} \mathrm{Cu}$ & $\begin{array}{c}\text { JENDL-3d } \\
\text { IRDF-82 }\end{array}$ & IRDF-90 & $\begin{array}{l}1.1075 \\
0.9313 \\
\end{array}$ & $\begin{array}{c}1.1096 \\
0.93029 \\
\end{array}$ & 7.41 & 7.07 \\
\hline 30. & ${ }^{90} \mathrm{Zr}(\mathrm{n}, 2 \mathrm{n})^{89} \mathrm{Zr}$ & JENDL-3d & IRDF-90 & 1.0395 & 1.041 & 2.72 & 2.74 \\
\hline 31. & ${ }^{83} \mathrm{Nb}(\mathrm{n}, \gamma)^{94 m} \mathrm{Nb}$ & JENDL-3 & ENDF/B-VI & 1.0143 & 0.975 & 12.59 & 10.20 \\
\hline 32. & ${ }^{93} \mathrm{Nb}(\mathrm{n}, 2 \mathrm{n})^{92 / \mathrm{m}} \mathrm{Nb}$ & JENDL-3d & IRDF-90 & 1.154 & 1.1447 & 10.00 & 10.07 \\
\hline 33. & ${ }^{83} \mathrm{Nb}\left(\mathrm{n}, \mathrm{n}^{\prime}\right)^{93 \mathrm{~m}} \mathrm{Nb}$ & JENDL-3d & IRDF-90 & 1.0503 & 1.052 & 7.23 & 6.96 \\
\hline 34. & ${ }^{98} \mathrm{Mo}(\mathrm{n}, \gamma)^{99} \mathrm{Mo}$ & ENDF/B-Va & JENDL-3 & 0.7947 & 1.042 & -NA-- & -NA-- \\
\hline 35. & ${ }^{115} \operatorname{In}\left(n, n^{\prime}\right)^{175 m_{I n}}$ & ENDF/B-Va & IRDF-90 & 0.9652 & 0.9644 & 2.56 & 2.56 \\
\hline 36. & ${ }^{127} I(n, 2 n)^{126} I$ & JENDL-3d & ENDF/B-VI & 1.202 & 1.2035 & 20.45 & 20.38 \\
\hline 37. & ${ }^{197} \mathrm{Au}(\mathrm{n}, \gamma){ }^{198} \mathrm{Au}$ & JENDL-3d & ENDF/B-VI & 0.995 & 1.001 & 0.84 & 0.17 \\
\hline 38. & ${ }^{197} \mathrm{Au}(\mathrm{n}, 2 \mathrm{n})^{196} \mathrm{Au}$ & JENDL-3d & IRDF-90 & 1.0317 & 1.0254 & 6.65 & 6.68 \\
\hline 39. & ${ }^{235} \mathrm{U}(\mathrm{n}, \mathrm{f})$ F.P. & JENDL-3d & ENDF/B-VI & 1.007 & 0.9883 & 0.44 & 0.22 \\
\hline 40. & ${ }^{238} \mathrm{U}(\mathrm{n}, \mathrm{f}) \mathrm{F} . \mathrm{P}$. & JENDL-3d & ENDF/B-VI & 1.013 & 1.0135 & 0.64 & 0.33 \\
\hline 41. & ${ }^{237} \mathrm{~Np}(\mathrm{n}, \mathrm{f}) \mathrm{F} . \mathrm{P}$. & JENDL-3d & ENDF/B-VI & 1.011 & 1.011 & 10.32 & 11.79 \\
\hline 42. & ${ }^{239} \mathrm{Pu}(\mathrm{n}, \mathrm{f}) \mathrm{F} . \mathrm{P}$ & JENDL-3d & ENDF/B-VI & 0.9999 & 1.0015 & 2.82 & 1.39 \\
\hline
\end{tabular}


This cross section library is being distributed to the dosimetry community; however, users should be aware that the QA assessment of the library has been restricted to the environments and sensors in use at the SNL RML. A version of the SAND-II iterative spectrum unfolding code has been interfaced with the SNLRML Library cross section compendium. This code is currently undergoing testing and is expected to be made available through RSIC by January 1994. A version of the LSL-M2 least-square spectrum adjustment code is currently being interfaced with the SNLRML library cross section compendium.

\section{EFFECT OF USING NEW CROSS SECTIONS}

There are significant differences between the general-usage (typically ENDF/B-V based) and new SNLRML-recommended dosimetry cross sections for some reactions. Many dosimetry reactions were found to differ in the region above $7 \mathrm{MeV}$. The ${ }^{63} \mathrm{Cu}(\mathrm{n}, \alpha){ }^{60} \mathrm{Co}$ reaction, is one example. In this case, despite the significant change ( $50 \%)$ in the shape of the cross section, tolding the cross section with a fission reactor spectrum results in very little (2-5\%) difference in the resulting activity. For most dosimetry reactions, the ENDF/B-V and ENDF/B-VI cross sections were in very good agreement below $7 \mathrm{MeV}$. The ${ }^{58} \mathrm{Fe}(\mathrm{n}, \gamma){ }^{59} \mathrm{Fe}$ reaction, was an exception. When this cross section is folded with typical fission reactor spectra, the resulting calculated activities from ENDF/B-V and ENDF/B-VI cross sections differ by 30 $60 \%$.

Table 3 shows the differences that can arise between dosimetry-quality cross sections for fast-burst and pool-type fission spectra for a subset of the reactions in the SNLRML. The cross section evaluator's covariance data were used to estimate the spectrum-averaged cross section uncertainty.

\section{CONCLUSION}

The status of available dosimetry cross section libraries has been reviewed. This review has resulted in the preparation of the SNLRML cross section compendium that includes the latest and most consistent dosimetry-oriented cross sections from all available evaluations. The contents of the SNLRML library include all dosimetry sensors (activation reactions, threshold reactions, fission reactions, and special damage sensors) that are in general use by the dosimetry community for the characterization of fission neutron spectra. The cross section compendium has been interfaced with spectrum determination cocles and found to produce consistent spectrum "unfolds" with more sensors than were possible with previous libraries. The SNLRML library is being made available to the general dosimetry community in order to encourage the use of a consistent cross section library for spectrum determination. The authors plan on updating the library as part of the RML quality assurance program.

\section{REFERENCES}

[1] "ENDF-201, ENDF/B-VI Summary Documentation," edited by P. F. Rose, Brookhaven National Laboratory Report BNL-NCS$1741,4^{\text {th }}$ Edition, October 1991.

[2] "ENDF-102, Data Formats and Procedures for the Evaluated Nuclear Data File ENDF-6," edited by P. F. Rose and C. L. Dunford, Brookhaven National Laboratory Report BNL-NCS-44945, July 1990, revised October 1991.

[3] "International Reactor Dosimetry File (IRDF-90)", assembled by N. P. Kocherov et al., International Atomic Energy Agency, Nuclear Data Section, IAEA-NDS-141 Rev. 0, August 1990.

[4] T. Asami, T. Nakagawa, M. Mizumoto, T. Narita, K. Shibata, S. Chiba, T. Fukahori, A. Hasegawa, S. Igarasi, "Status of Japanese Evaluated Nuclear Data Library Version 3," Nuclear Data for Science and Technology (1988 MITO), pp. 533-536, JAERI, 1988.

[5] V. N. Manokhin, "BROND, USSR Evaluated Neutron Data Library," International Atomic Energy Agency Nuclear Data Services, Documentation Series of the IAEA Nuclear Data Section, IAEA-NDS-90, Rev. 2, October 1989.

[6] C. Nordborg, H. Gruppelaar, M. Salvatores, "Status of the JEF and EFF Projects," pp. 782 in Nuciear Data for Science and Technology, editor S. Qaim, Springer-Verlag, Berlin, 1992.

[7] C. Y. Fu, D. M. Hetrick, "Experience in Using the Covariances of Some ENDF/B-V Dosimetry Cross Sections: Proposed Improvements and Addition of Cross-Reaction Covariance," Proceedings of the Fourth ASTM-Euratom Symposium on Reactor Dosimetry: Radiation Metrology Techniques, Data Bases, and Standardization, Volume II, conference held at the National Bureau of Standards, Gaithersburg, Maryland on March 22-26, 1982, pp. 877 - 887, Report number NUREG/CP-0029, CONF. 820321/V2. The latest GLUCS library contains 14 dosimetry reactions, was updated in January 1993.

[8] A. B. Pashchenko, et al., "FENDL-2 and Associated Benchmark Calculations," International Atomic Energy Agency (Austria), International Nuclear Data Committee, report INDC(NDS)-260/LF, March 1992. 
[9] C. Dunjui, "Evaluation of Cross Sections for Dosimetry Reactions," Chinese Nuclear Data Centre, Institute of Atomic Energy, International Atomic Energy Agency report INDC(CPR)-024, October 1991.

[10] T. Guoyou, F. Jihong, C. Wentian, B. Shanglian, "Evaluation of Neutron Nuclear Data of Np-237 For CENDL-2," Physics Department, Nankai University, P. R. of China, International Atomic Energy Agency report INDC(CPR)-023, October 1991.

[11] P. J. Griffin, J. G. Kelly, T. F. Luera, "Effect of New Cross Section Evaluations on Spectrum Determinations," SAND92-0093, Sandia National Laboratories, presented at the $29^{\text {th }}$ International Nuclear and Space Radiation Effects Conference held on July 13-17, 1992 in New Orleans, Louisiana. Conference proceedings are published in IEEE Transactions on Nuclear Science, Vol. 39, No. 6, pp. 2078-2085, Dec. 199 ?.

[12] P. J. Griffin, J. G. Kelly, T. F. Luera, "Effect of ENDF/B-VI Cross Sections on Neutron Dosimetry," Proceedings of the Seventh ASTM-Euratom Symposium on Reactor Dosimetry, held in Strassbourg, France on August 27-31, 1990, G. Tsotridis, R. Dierckx, P. D'Hondt editors, Kluwer Academic Publishers, 1990, pp. 669-675.

[13] W. N. McElroy, S. Berg, T. Crockett, and R. Hawkins, "A Computer-Automated Iterative Method for Neutron Flux Spectral Determination by Foil Activation," AFWL-TR-67-41, Vol. 1, Air Force Weapons Laboratory, Kirtland, New Mexico, July 1967.

[14] F. W. Stallman, "LSL-M2: A Computer Program for Least-Squares Logarithmic Adjustment of Neutron Spectra," NUREG/CR4349, ORNL/TM-9933, March 1985.

[15] R. J. Howerton, D. E. Cullen, R. C. Haight, M. H. MacGregor, S. T. Perkins, and E. F. Plechaty, "The LLL Evaluated Nuclear Data Library (LENDL): Evaluation Techniques, Reaction Index, and Description of Individual Evaluations," Lawrence Livermore Laboratory report UCRL-50400, Vol. 15, Part A, September 1975.

[16] W. L. Zijp, H. J. Nolthenius, G. C. H. M. Verhaag, "Cross-Section Library DOSCROS84 (in a 640 group structure of the SANDII type)," Netherlands Energy Research Foundation ECN, Petten, report ECN-160, October 1984.

[17] D. C. Larson, D. M. Hetrick, S. J. Epperson. N. M. Larson, "Evaluation of $28,29,30$ Si Neutron Induced Cross Sections for ENDF/B-VI", Oak Ridge National Laboratory, Report ORNL-TM-11825, to be published.

[18] D. L. Smith, Argonne National Laboratory, private communication to P. J. Griffin on October 1992. Contents included a letter and a flopry disk.

[19] B. Strohrnaier, "New Issue of Nuclear Model Calculations of Cross Sections for Neutron-Induced Reactions on ${ }^{93} \mathrm{Nb}$ to 20 MeV," Ans. Nucl. Energy, Vol. 16, No. 9, pp. 461-470, 1989.

[20] A. D. Carlson, W. P. Poenitz, G. M. Hale, R. W. Peelle, D. C. Dodder, C. Y. Fu, W. Mannhart, "The ENDF/B-VI Neutron Cross Section Measurement Standards," U. S. Department of Commerce Technology Administration National Institute of Standards and 'Technology report NISTIR 5177, May 1993.

[21] D. M. Hetrick, Oak Ridge National Laboratory, private communication to P. J. Griffin on December 4, 1991 and on January 13 , 1992. Contents included a letter and a floppy disk.

[22] W. Mannhart, D. L. Smith, J. W. Meadows, "The Discrepancy Between Differential and Integral Data on Ti-47(n,p)," in the proceedings from the American Nuclear Society Proceedings on a Topical Meeting on Advances in Nuclear Engineering Computation and Radiation Shielding, Santa Fe, New Mexico, April 9-13, 1989,University of New Mexico Publications, Ed. M. L. Hall, pp. 577-580.

[23] M. Wagner, "Update of the Evaluation of the Cross Sections for the Neutron-Dosimetry Reactions ${ }^{19} F(n, 2 n){ }^{18} F$ and ${ }^{93} \mathrm{Nb}(\mathrm{n}, 2 \mathrm{n})^{92 \mathrm{~m}} \mathrm{Nb}$," Institut fur Radiumforschung und Kernphysik der Universitat Wien, International Atomic Agency report INDC(AUS)-014, October 1991.

[24] S. Iwasaki, M. Sakuma, N. Odano, H. Suda, K. Sugiyama, "Ratio Tests of Dosimetry Cross-Sections for ${ }^{93} \mathrm{Nb}(\mathrm{n}, 2 \mathrm{n}){ }^{92 \mathrm{~m}_{\mathrm{Nb}} \text { and }}$ ${ }^{197} \mathrm{Au}(\mathrm{n}, 2 \mathrm{n}){ }^{196} \mathrm{Au}$ to ${ }^{27} \mathrm{Al}(\mathrm{n}, \alpha){ }^{24} \mathrm{Na}$ Reactions," Progress in Nuclear Energy, Vol. 26, No. 3, pp. 231-217, 1991.

[25] M. Nakazawa, K. Kobayashi, S. Iwasaki, T. Iguchi, K. Sakurai, Y. Ikeda, T. Nakagawa, JAERI 1325, Japan Atomic Energy Research Institute, Tokai, Japan, 1992.

[26] P. J. Griffin, J. G. Kelly, T. F.Luera, J. VanDenburg, "SNL RML Recommended Dosimetry Cross Section Compendium," Sandia National Laboratories, Albuquerque, NM, report SAND92-0094, August 1993.

[27] W. Mannhart, "Status of CF-252 Neutron Spectrum as a Standard," Reactor Dosimetry: Methods, Applications, and Standardization, ASTM STP 1001, Harry Farrar IV and E. P. Lippincott, Eds., American Society for Testing and Materials, Philadelphia, 1989, pp. 340-347.

[28] C. Y. Fu, "A Re-Evaluation of ${ }^{32} \mathrm{~S}(\mathrm{n}, \mathrm{p})$ Cross Sections From Threshold to $5 \mathrm{MeV}$," in the proceedings from the American Nuclear Society Proceedings on a Topical Meeting on Advances in Nuclear Engineering Computation and Radiation Shielding. Santa Fe, New Mexico April 9-13, 1989,University of New Mexico Publications, Ed. M. L. Hall.

[29] J. W. Meadows, D. L. Smith, M. M. Bretscher, S. A. Cox, "Measurement of 14.7 MeV Neutron-Activation Cross Sections for Fusion," Ann. Nucl. Energy, Vol. 14, No. 9, pp. 489-497, 1987.

[30] R. E. MacFarlane, D. W. Muir, R. M. Boicourt, "The NJOY Nuclear Data Processing System, Volume 1: User's Manual," LA9303-M, ENDF-324, May 1982. The code is available as PSR-171 from the Oak Ridge National Laboratory (ORNL) Radiation Shielding Information Center (RSIC). 

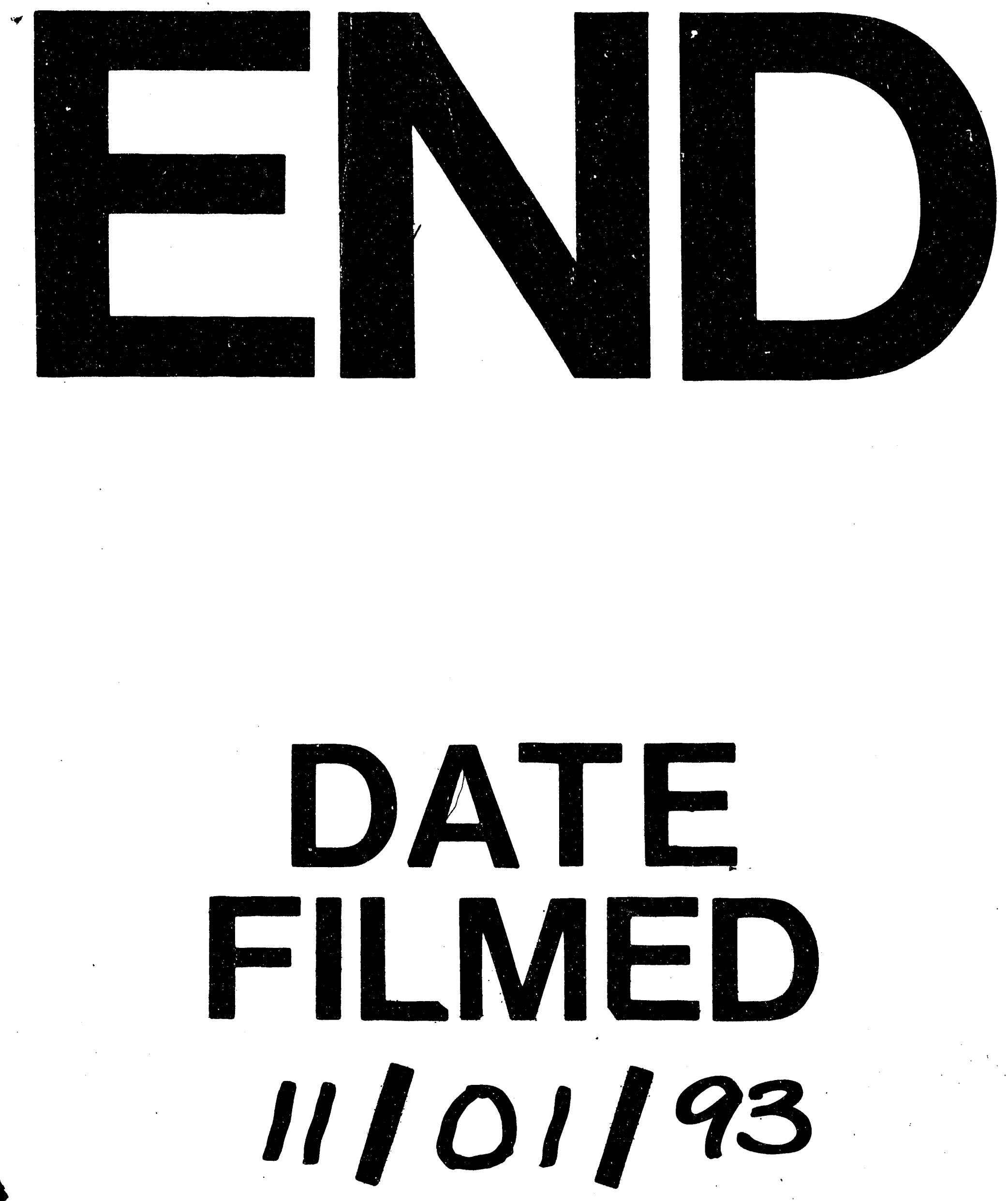

1 